SCIENTIFIC REPORT

\title{
An evaluation of the change in activity and workload arising from diabetic ophthalmology referrals following the introduction of a community based digital retinal photographic screening programme
}

\author{
P H Scanlon, S Carter, C Foy, D Ratiram, B Harney
}

Br J Ophthalmol 2005;89:971-975. doi: 10.1136/bjo.2004.060723

\begin{abstract}
Aims: To determine how the workload of an ophthalmology department changed following the introduction of an organised retinal screening programme.

Methods: Information was collected from the hospital medical record of people with diabetes attending eye clinics over 4 years. The first year was before screening, the next 2 years the first round, and the fourth year the second round.

Results: The total number of people with diabetes referred each year over the 4 year period was 853,954, 974, 1051 consecutively. The number of people with diabetes in the county rose by 1400 per annum. The total number of referrals for an opinion about diabetic retinopathy was 227, $333,363,368$, for cataract was $64,57,77,93$, and for glaucoma was $57,62,61,68$. The total number of patients referred for laser treatment over the 4 years was 77,124 , 111 , and 63

Conclusion: This study suggests that the workload in the eye clinic increases in the first round of screening but in subsequent rounds it does not fall below the pre-screening level, except for laser treatment. This may be partly because of increasing numbers of people with diabetes. With the introduction of a national screening programme, this has significant workload implications for the National Health Service.
\end{abstract}

l: 1995-6 Gloucestershire Primary Care Clinical Audit Group coordinated a countywide audit, ${ }^{1}$ which identified 9556 people with diabetes over the age of $16(2.1 \%$ of the county's population aged 16 and over). In October 1998, a mobile digital photographic screening programme was introduced, funded by Gloucestershire Health Authority, with contributions from charitable sources.

In 2000, the National Screening Committee produced their recommendations ${ }^{2-4}$ for a national screening programme and estimated the effect on treatment workload and associated costs.

The aim of this study was to determine how the workload of an ophthalmology department changes following the introduction of an organised retinal screening programme.

\section{MATERIALS AND METHODS \\ Design}

A retrospective collection of data from the hospital medical records after electronic identification of diabetic patients attending the eye clinic was carried out by matching retinal screening numbers with eye clinic codes.

\section{Sample group}

The sample group consisted of all people known to have diabetes in Gloucestershire aged 16 years and over attending as new patients to eye clinics in Gloucestershire over 4 years. This case review included the year before the introduction of screening, the 2 years of the first round of screening, and first year of the second round of screening.

\section{Exclusion criteria}

Those aged less than 16 years. We do not collect information on people with diabetes under 16 years for our screening service at present. There are approximately 170 children and teenagers in this age group under the care of Gloucestershire paediatricians.

\section{Justification of sample size}

The number of people with diabetes attending as new patients to eye clinics in Gloucestershire over a 3 year period was 2700 and it was expected to be 3600 for the 4 years when the data was collected in October 2001.

In all, 8566 people with diabetes were screened in the first round of screening in Gloucestershire with 434 (5.1\%) referred with referable diabetic retinopathy ( 33 proliferative, 102 pre-proliferative, and 299 maculopathy). Our previous study ${ }^{5}$ showed a sensitivity of $88 \%$ in detection of referable diabetic retinopathy (DR). It follows that a missed case (false negative) might occur in five proliferative patients out of $8566(0.06 \%)$ people with diabetes and in 41 maculopathy patients $(0.48 \%)$. Patients missed in screening, by being false negatives, will be picked up subsequently by natural presentation via other routes of referral and to identify these small numbers required looking at all 3600 records. In this study complete coverage was intended and there was therefore no sampling. When the study was designed we anticipated an annual screening service and, hence, data collection for a 3 year period and the design was altered to 4 years when it became clear that the first round of screening would take 2 years to complete (because of the higher than anticipated workload for the screeners).

\section{Methods}

All people with diabetes aged 16 years and over in Gloucestershire have been given a retinal screening number. This includes those responding and those not responding to the screening invitation. The diabetic registers of all of the 85 general practices in Gloucestershire were used to compile a list of all people known to have diabetes. A total of 12300 people with diabetes $(2.6 \%$ of the population) had been

Abbreviations: DR, diabetic retinopathy; GDESS, Gloucestershire Diabetic Eye Screening Service 


\begin{tabular}{|c|c|c|c|c|}
\hline $\begin{array}{l}\text { Annual new diabetic } \\
\text { referrals to eye clinics } \\
\text { in Gloucestershire }\end{array}$ & $\begin{array}{l}\text { East Glos } \\
\text { attendances }\end{array}$ & $\begin{array}{l}\text { West Glos } \\
\text { attendances }\end{array}$ & $\begin{array}{l}\text { Total } \\
\text { attendances }\end{array}$ & $\begin{array}{l}\text { Notes not } \\
\text { examined }\end{array}$ \\
\hline \multicolumn{5}{|l|}{ Year } \\
\hline $1997-8$ & 393 & 460 & 853 & 7 \\
\hline $1998-9$ & 451 & 503 & 954 & 7 \\
\hline 1999-2000 & 469 & 505 & 974 & 8 \\
\hline 2000-1 & 483 & 568 & 1051 & 23 \\
\hline Total & 1796 & 2036 & 3832 & 45 \\
\hline
\end{tabular}

identified when this grant application was considered in February 2001 reaching 13239 in October 2001. Patients with retinal screening numbers on the east Gloucestershire PAS system were matched against all new patient attendance at eye clinic codes on the same system in February 2001 and again in October 2001. For west Gloucestershire, all patients with retinal screening numbers were matched against all new patient attendance to west Gloucestershire eye clinics using NHS number, surname, forename, and date of birth. The retrospective identification of these people with diabetes attending eye clinics was undertaken once the first round of screening had been completed and an accurate list of people with diabetes aged $>16$ years in the county had been collected.

The medical records from all new diabetic referrals to eye outpatient departments in Gloucestershire over 4 years were examined and the following information was recorded:

- Patient details

- Type of diabetes care

- Date of referral letter

- Date of clinic appointment

- Route of referral

- Reason given for referral

- Date of previous retinal examination (if known)

- Date of previous retinal photography (if applicable)

- Best corrected visual acuity recorded in each eye (Snellen)

- Grade of retinopathy in worse eye

- Other eye disease

- Action/outcome.

The definition of referable DR used in this study was described in two previous studies. ${ }^{5}{ }^{6}$ The reason for using referable DR in this study was because the screening service has a level at which referral to an eye department is felt to be necessary, which may not be at such an advanced level as may require laser treatment. In the context of the current study, sight threatening DR was used to describe a retinopathy level thought to be at a stage requiring laser treatment for maculopathy or pre-proliferative/proliferative DR. In Gloucestershire, laser is usually applied to treat maculopathy as described in the Early Treatment Diabetic Retinopathy Study ${ }^{78}$ and pre-proliferative DR is usually followed up carefully and laser applied when proliferative DR is detected.

\section{RESULTS}

Annual new diabetic referral rate to eye clinics in Gloucestershire over a 4 year period

Over the 4 year period 3877 people with diabetes were identified electronically as having attended Eye clinics in Gloucestershire as new patients (table 1). This included patients who were already registered at the eye clinic who attended as an emergency at a date between their booked

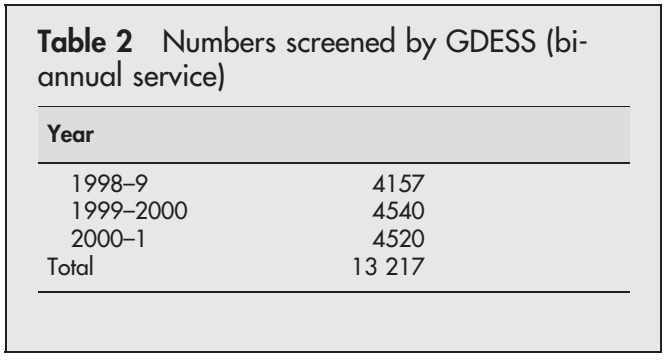

appointments, as routinely recorded as a "new patient referral" on our PAS system.

There has been a progressive rise in new patient attendances of people with diabetes in the eye clinic during the 4 years starting in 1997-8 with annual rises from 853 (pre-screening) to 954, 974, and 1051.

Of the 3877 patients attending eye clinics it was possible to examine the notes of 3832. Notes were not available for 45 patients over the 4 year period, and for eight patients there was no evidence of a clinic appointment in the notes.

During the first 3 years of screening by the Gloucestershire Diabetic Eye Screening Service (GDESS) there was an increase in the numbers screened per annum from 4157 to 4520 (table 2).

\section{The number of people with diabetes in the county: annual increases}

In the 1996 Gloucestershire audit there were 9566 people with diabetes identified in the county. After the first round of screening in October 2000 there were 11909 identified. The following October 2001 there were 13 239. This number has continued to rise at a rate of approximately 1400 per annum and was 15433 in May 2003 (table 3).

\section{The reason given for attendance}

The commonest reasons for referral are "reduced vision" and "retinopathy seen."

Other reasons given for referral are shown in table 4 and the reason itemised where it gave rise to more than 100 referrals.

$\begin{array}{lc}\text { Table } 3 & \text { Number of adult diabetic people in } \\ \text { Gloucestershire (aged }>16 \text { years) }\end{array}$


Table 4 Reason given for referral

\begin{tabular}{|c|c|c|c|c|c|}
\hline & $1997-8$ & 1998-9 & 1999-2000 & 2000-1 & Total \\
\hline Opinion about DR seen & 227 & 333 & 363 & 368 & 1291 \\
\hline Reduced vision & 288 & 272 & 232 & 221 & 1013 \\
\hline Cataract opinion & 66 & 59 & 77 & 98 & 300 \\
\hline Glaucoma opinion & 57 & 62 & 61 & 68 & 248 \\
\hline Pain/discomfort/itchiness/grittiness/headaches & 48 & 31 & 36 & 30 & 145 \\
\hline Lids & 35 & 14 & 23 & 43 & 115 \\
\hline Non-specific retinal opinion & 20 & 29 & 29 & 25 & 103 \\
\hline Poor view & 19 & 19 & 28 & 34 & 100 \\
\hline Other reasons & 143 & 161 & 169 & 168 & 641 \\
\hline Total & 903 & 980 & 1018 & 1055 & 3956 \\
\hline One reason & 707 & 828 & 824 & 853 & 3212 \\
\hline Two reasons & 98 & 76 & 97 & 101 & 372 \\
\hline Missing reasons & 48 & 50 & 53 & 97 & 248 \\
\hline Total attendances & 853 & 954 & 974 & 1051 & 3832 \\
\hline
\end{tabular}

The workload and source of the referral for "reduced vision"

The numbers referred with "reduced vision" decreased over the 4 years from 288 in year 1 (pre-screening) to 272, 232, and 221 and as a percentage of those referred, this was $33.8 \%$, $28.5 \%, 23.8 \%$, and $21 \%\left(\chi^{2}\right.$ for trend $\left.44.1, \mathrm{p}<0.0001\right)$.

The common outcomes for these patients are shown in table 5 (NB, more than one outcome is possible).

The proportion of patients referred with reduced vision who were discharged at first clinic attendance decreased from $20.1 \%$ (pre-screening) to $17.3 \%, 13.8 \%$, and $8.6 \%$ in subsequent screening years $\left(\chi^{2}\right.$ for trend 13.7, $\left.\mathrm{p}<0.001\right)$.

The number of patients referred for reduced vision who were listed for laser for DR at first clinic attendance decreased over the 4 years from 26 (pre-screening) to 18, eight, and seven and as a percentage of those referred with reduced vision this was $8 \%, 5.8 \%, 3.1 \%$, and $2.9 \%\left(\chi^{2}\right.$ for trend 9.1 , $\mathrm{p}=0.003)$.

The number of patients referred for reduced vision who were listed for cataract surgery at first clinic attendance decreased over the 4 years from 112 (pre-screening) to 100 , 89 , and 99 and as a percentage of those referred with reduced vision this was $34.3 \%, 32.1 \%, 34.9 \%$, and $41.6 \%\left(\chi^{2}\right.$ for trend 3.27, $\mathrm{p}=0.07$ ).

\section{The workload and source of the referral for background and referable diabetic retinopathy (tables 4 and 5)}

The number of patients referred who were found to have no DR during the 4 years did not vary greatly (484 prescreening, 473, 466, and 512) but since the number of people referred increased the percentage found to have no DR decreased from $56.7 \%$ to $49.6 \%, 47.8 \%, 48.7 \%$ ( $\chi^{2}$ for trend $11.5, \mathrm{p}=0.001$ ).

The number of patients referred who were found to have mild to moderate background DR increased during the first round of screening and remained at a higher level (162 prescreening, 196, 194, and 212) and as a percentage of those referred, this was $19 \%, 20.5 \%, 19.9 \%$, and $20.2 \%\left(\chi^{2}\right.$ for trend $0.22, \mathrm{p}=0.64$ ).

The number of patients referred who were found to have referable retinopathy showed a rise during the first two rounds of screening. There was then a slight reduction but not to the level of the year before the screening programme commenced (172 pre-screening, 247, 268, 236) and as a percentage of those referred, this was $20.2 \%, 25.9 \%, 27.5 \%$, and $22.5 \%\left(\chi^{2}\right.$ for trend $\left.1.22, \mathrm{p}=0.27\right)$.

The source of referral where referable DR was found in the eye clinic was GP $(38,19,16,21)$, optometrist (via GP) (60, $49,30,34)$, physician $(35,49,28,24)$ and eye screening service (GDESS) (0 pre-screening, 71, 155, 115).

The sources of referral where "an opinion about DR seen" was requested or where any diabetic retinopathy was found in the eye clinic are summarised in table 6.

The source of referral for "an opinion about DR seen" or where any diabetic retinopathy was found in the eye clinic decreased from general practitioners but not from optometrists or physicians.

The eye screening service (GDESS) showed a rise in referrals for "an opinion about DR seen" from 103 in the first year of screening to 237 in the second and decreased to 190 in the first year of the second round of screening. As a percentage of those referred for "an opinion about DR seen" the rise was from $30.9 \%$ to $65.3 \%$ and decreased in the third year to $51.6 \%\left(\chi^{2}\right.$ for trend $\left.27.6, p<0.001\right)$. Similarly, The eye screening service (GDESS) showed a rise in numbers where diabetic retinopathy was found in the eye clinic from 104 in the first year to 233 in the second and decreased to 184 in the first year of the second round of screening. As a percentage of those referred where diabetic retinopathy was found in the eye clinic this was $25.7 \%$ rising to $54.2 \%$ and falling in the third year to $45.2 \%$ ( $\chi^{2}$ for trend $\left.31.7, \mathrm{p}<0.001\right)$. For patients

Table 5 Common outcomes in those referred with reduced vision

\begin{tabular}{lccccc}
\hline & $\mathbf{1 9 9 7 - 8}$ & $\mathbf{1 9 9 8 - 9}$ & $\mathbf{1 9 9 9 - 2 0 0 0}$ & $\mathbf{2 0 0 0 - 1}$ & Total \\
\hline Discharged after first appointment & 58 & 47 & 32 & 19 & 156 \\
Listed for cataract surgery & 112 & 100 & 89 & 99 & 400 \\
Clinic review for other eye disease & 81 & 84 & 79 & 74 & 318 \\
Clinic review for diabetic retinopathy & 17 & 32 & 20 & 17 & 86 \\
Listed for laser for DR & 26 & 18 & 8 & 7 & 48 \\
Listed for YAG laser capsulotomy & 14 & 15 & 11 & 8 & 34 \\
Fluorescein angiography & 7 & 8 & 10 & 9 & 19 \\
Registered partially sighted, partial BD8 & 8 & 5 & 2 & 3 & 1132 \\
Registered blind, full BD8 & 4 & 3 & 255 & & \\
Total above & 327 & 312 & & & \\
\hline NB: more than one outcome was possible for a referral.
\end{tabular}


Table 6 The change in workload during the first round of screening (middle 2 years)

\begin{tabular}{|c|c|c|c|c|c|c|c|c|c|c|}
\hline & \multicolumn{5}{|c|}{$\begin{array}{l}\text { Source of referral to eye clinic with referral criteria of opinion } \\
\text { about DR seen: }\end{array}$} & \multicolumn{5}{|c|}{ Source of referral to eye clinic with any DR found in clinic } \\
\hline & $1997-8$ & $1998-9$ & 1999-2000 & $2000-1$ & Total & $1997-8$ & $1998-9$ & 1999-2000 & 2000-1 & Total \\
\hline Eye screening service & 0 & 103 & 237 & 190 & 530 & 0 & 104 & 233 & 184 & 521 \\
\hline GP and optician & 96 & 101 & 54 & 92 & 343 & 124 & 119 & 73 & 108 & 424 \\
\hline Physician & 56 & 85 & 56 & 61 & 258 & 64 & 90 & 65 & 57 & 276 \\
\hline GP & 62 & 30 & 13 & 22 & 127 & 88 & 58 & 37 & 43 & 226 \\
\hline Within eye department & 10 & 11 & 3 & 3 & 27 & 13 & 17 & 11 & 6 & 47 \\
\hline A\&E dept & 1 & 1 & 0 & 0 & 2 & 7 & 7 & 4 & 2 & 20 \\
\hline Self referral & 0 & 0 & 0 & 0 & 0 & 3 & 7 & 3 & 6 & 19 \\
\hline Other sources & 2 & 2 & 0 & 0 & 2 & 2 & 3 & 4 & 1 & 10 \\
\hline Total & 227 & 333 & 363 & 368 & 1289 & 301 & 405 & 430 & 407 & 1543 \\
\hline
\end{tabular}

referred from screening with maculopathy or pre-proliferative DR (92\% of referable DR), there was a lag time of approximately 13 weeks from screening to being seen in the eye clinic.

\section{The workload and source of referral of patients with diabetes referred for cataract opinion and reduced vision and the numbers listed for cataract surgery} The total number of referrals specifically for cataract opinion was $66,59,77,98$. The source of these was GP $(19,14,13$, 19), optometrist (via GP) $(40,35,39,62)$, physician $(5,1,2$, $2)$, eye screening service (GDESS) (0 pre-screening, 4, 17, $12)$, and other sources $(2,5,6,3)$.

The total number of people with diabetes listed for cataract surgery at first visit remained fairly stable (158 pre-screening, 143, 145, and 168) and as a percentage of those referred, this was $18.5 \%, 15 \%, 14.9 \%$, and $16 \%\left(\chi^{2}\right.$ for trend 1.73 , $\mathrm{p}=0.19)$.

The workload and source of referral of patients with diabetes referred specifically for a glaucoma opinion and the numbers of patients with diabetes actually diagnosed with glaucoma

The total number of referrals specifically for glaucoma opinion was 57, 62, 61, and 68. The source of these was GP $(2,8,3,2)$, optometrist (via GP) $(51,42,25,52)$, physician $(3$, $3,2,3)$, eye screening service (GDESS) $(0,8,28,6)$, and other sources $(1,1,3,5)$.

The number of patients with diabetes actually diagnosed with glaucoma was $55,54,55$, and 62 . The source of referral of those actually diagnosed with glaucoma (even if the referral reason did not suggest this) was GP $(11,12,8,12)$, optometrist (via GP) $(42,32,19,34)$, physician $(2,6,5,5)$, eye screening service (GDESS) (0 pre-screening, 3, 17, 7), and other sources $(0,1,6,4)$.

Over the 4 years the false positive referrals for glaucoma were five out of 15 (33\%) for GPs, 88 out of 170 (52\%) for optometrists, six out of 11 (55\%) for physicians, and 26 out of $42(62 \%)$ for the 3 years of the diabetic eye screening service.

\section{Non-attenders for screening presenting with retinopathy}

During the year 2000-1, 55 people who declined their invitation to attend the first round of screening presented in clinic with referable DR.

\footnotetext{
Number of new patients referred for laser treatment (and type of laser treatment) and numbers of laser treatment sessions required over the following year The total number of new patients referred for laser treatment over the 4 years was 77 pre-screening, 124, 111, and 63 and
}

as a percentage of those referred the percentage was $9 \%, 13 \%$, $11.4 \%$, and $6 \%$.

Numbers of new patients referred for laser treatment for maculopathy over the 4 years were $61,94,81$, and 36 . The total number of laser treatment sessions required for these patients was $89,136,119$, and 62 .

Numbers of new patients referred for laser treatment for pre-proliferative/proliferative over the 4 years were 16, 30, 30, and 27 . The total number of laser treatment sessions required for these patients was 82, 146, 146, and 137.

The total number of laser treatment sessions for sight threatening diabetic retinopathy for new patients over the 4 years was 171, 282, 265, and 199.

\section{DISCUSSION}

The number of people with diabetes referred to the eye department continued to rise over the 4 years of the study, as did the number of referrals for an opinion about diabetic retinopathy. The figures have been measured against a background of a rise of approximately 1400 per annum in the number of people with diabetes in the county. The number of patients referred for laser treatment rose from a pre-screening figure of 77 to 124 and 111 during the first round of screening and returned to 63 in the fourth year. A $\chi^{2}$ for trend test was not performed as there was no expectation of an increasing trend over the 4 years of the study.

The percentage of referrals found to have no DR decreased from $56.7 \%$ to $48.7 \%$ over the 4 years and those referred with reduced vision declined from $33.8 \%$ to $21 \%$ during this period. Of those who were referred with reduced vision, the percentage of these who were discharged at first clinic visit decreased from $20.1 \%$ to $8.6 \%$ and the percentage of these patients listed for laser for sight threatening DR decreased from $9 \%$ to $3.2 \%$. These trends suggest to the authors that the quality of referral criteria improved during this time.

The figures consistently show a doubling of the numbers referred by the eye screening service in each category from the first year of the first round of screening to the second year of the first round of screening, despite the same numbers of patients being screened. Screening in the first round commenced with one camera in October 1998 and a second camera was introduced in January 1999 with the rate of screening increasing during the first year for both screeners as they became more experienced. Hence, a proportionately greater number were screened in the latter 3 months of the first year of screening. For this group there was a lag time of 13 weeks from screening to being seen in the eye clinic, which explains the increased numbers appearing in the eye clinic in the second year of screening.

Following a survey in 2000 of screening programmes in the South-West Region, Freudenstein and Verne published an 
editorial in the $B M J .^{9}$ They found a significant difference in rates of referral from screening programmes for cataract and glaucoma depending on criteria used for referral. In this study, the eye screening service did not have a significant impact on referrals for cataract or glaucoma.

This workload study has shown continuing referrals from other sources after the introduction of the screening programme. Referral for eye conditions other than retinopathy accounts for a proportion of these. Although referrals for an opinion about diabetic retinopathy decreased from GPs there was no decrease from optometrists who have always been a greater source of referral or from physicians who refer a smaller number. Our current screening programme is only offered every 2 years and this may have been an additional factor in the continued numbers of referrals from optometrists and in the ophthalmology workload. It is hoped that, with an annual programme, a significant number of annual review patients might be discharged to an annual screening photographic review.

The current study supports the reports from the literature that show a steady rise in incidence of diabetes ${ }^{10-13}$ and related complications ${ }^{14}$ in all age groups, both in the United Kingdom and worldwide. This is mostly because of a rising incidence of type 2 diabetes associated with an epidemic of obesity. ${ }^{15}$ A change in the WHO definition of diabetes ${ }^{16}$ and improved identification and reporting of diabetes have made a much smaller contribution.

This study has shown a progressive rise in workload related to the epidemic of diabetes, which will increase the pressure on ophthalmology services.

\section{ACKNOWLEDGEMENTS}

We thank Mark Histed for his assistance with examining case records and Solon Asteriadis and Denize Atan for their work on a laser treatment audit in Gloucestershire, which improved the quality of the data presented on laser treatment.

\section{Authors' affiliations}

P H Scanlon, S Carter, D Ratiram, B Harney, Gloucestershire Eye Unit, Cheltenham General Hospital, Cheltenham GL53 7AN, UK C Foy, Gloucestershire R \& D Support Unit, Cheltenham General Hospital, Cheltenham GL53 7AN, UK
Funding: one year grant from the South West R\&D Directorate in September 2001.

Competing interests: none declared

Correspondence to: Dr P H Scanlon, Gloucestershire Eye Unit, Cheltenham General Hospital, Sandford Road, Cheltenham GL53 7AN, UK; peter.scanlon@glos.nhs.uk

Accepted for publication 3 February 2005

\section{REFERENCES}

1 Clifford R, PCCAG. An audit on the care of adult diabetic patients in Gloucestershire. Cheltenham: Gloucestershire Primary Care Clinical Audit Group (PCCAG), 1996:1-54 (all).

2 National Screening Committee. Preservation of sight in diabetes: a risk reduction programme: www. diabetic-retinopathy.screeening.nhs.uk, 2000.

3 Gillow JT, Gray JA. The National Screening Committee review of diabetic retinopathy screening. Eye $2001 ; 15(\mathrm{Pt} 1): 1-2$.

4 Garvican L, Clowes J, Gillow T. Preservation of sight in diabetes: developing a national risk reduction programme. Diabet Med 2000;17:627-34.

5 Scanlon PH, Malhotra R, Thomas G, et al. The effectiveness of screening for diabetic retinopathy by digital imaging photography and technician ophthalmoscopy. Diabet Med 2003;20:467-74.

6 Scanlon PH, Malhotra R, Greenwood RH, et al. Comparison of two reference standards in validating two field mydriatic digital photography as a method of screening for diabetic retinopathy. Br J Ophthalmol 2003;87:1258-63.

7 Early Treatment Diabetic Retinopathy Study Research Group. Photocoagulation for diabetic macular edema. Early Treatment Diabetic Retinopathy Study report number 1. Arch Ophthalmol 1985;103:1796-806.

8 Early Treatment Diabetic Retinopathy Study Research Group. Treatment techniques and clinical guidelines for photocoagulation of diabetic macular edema. Early Treatment Diabetic Retinopathy Study Report Number 2. Ophthalmology 1987;94:761-74.

9 Freudenstein U, Verne J. A national screening programme for diabetic retinopathy. Needs to learn the lessons of existing screening programmes. BMJ 2001;323:4-5.

10 Amos AF, McCarty DJ, Zimmet P. The rising global burden of diabetes and its complications: estimates and projections to the year 2010. Diabet Med 1997; 14(Suppl 5):S1-85.

11 Mokdad AH, Ford ES, Bowman BA, et al. Diabetes trends in the US: 19901998. Diabetes Care 2000;23:1278-83.

12 Mokdad AH, Ford ES, Bowman BA, et al. The continuing increase of diabetes in the US. Diabetes Care 2001;24:412.

13 Ehtisham S, Barrett TG, Shaw NJ. Type 2 diabetes mellitus in UK children -an emerging problem. Diabet Med 2000;17:867-71.

14 Fitzsimons B, Wilton L, Lamont $T$, et al. The Audit Commission review of diabetes services in England and Wales, 1998-2001. Diabet Med 2002;19(Suppl 4):73-8.

15 Sorensen TI. The changing lifestyle in the world. Body weight and what else? Diabetes Care 2000;23(Suppl 2):B1-4.

16 World Health Organization. Definition, diagnosis and classification of diabetes mellitus and its complications. Geneva: WHO, 1999:1-66. 